\title{
Application of Computer Network in Informatization Construction Management
}

\author{
Wan Wendong and Liao Feng \\ (Jiangxi Technical College of Manufacturing, Nanchang, 330095)
}

Keywords: Computer network; Informatization construction; Management

\begin{abstract}
In recent years, science and technology have been widely used in the development and construction of various fields, among which computer network technology has achieved good results in a short period of time and is more important for people's lives and work. Computer network technology in the process of popularization of people's livelihood, the various fields of business construction are also affected by the computer. In the information-based social environment, the degree of informatization construction has become increasingly critical for the development and construction of various fields. How to improve the level of information construction is a problem in the development and construction. The application of computer network technology in information construction can have an important impact on information construction. This article takes the application of computer network technology in the hospital information construction as the research object, analyzes the current development and construction status and the problems that need to be faced, hoping to help the hospital information construction.
\end{abstract}

\section{Introduction}

In the new century, China's social and economic construction has made tremendous achievements. With the continuous improvement of the people' s living standards, higher requirements have been put forward for the development of the medical and health undertakings, especially as the country increasingly attaches importance to the development of public health and medical services. Next, the reform of the medical system in our country is gradually on the agenda. With the rapid development of informatization, computer network technology has been widely used in hospital clinical management and has provided strong technical support for the advancement of China's medical and health undertakings. Computer technology is an important means for hospitals to carry out informatization construction, on the other hand, It is also a powerful weapon for continuously improving the level of public services in hospitals. The information-based revolution in hospitals has become a development trend.

\section{The Importance of Computer Network Technology in Hospital Information Management}

Today, with the deepening of informationization, computer network technology has become an important tool for hospital management. It has an important impact on the hospital's work efficiency and work quality. If you do not pay attention to this aspect, it may cause hospital management problems andcause huge losses to the hospital.

(1) Strengthen the security of information systems and increase work efficiency.

Informatization construction in hospitals is a highly professional job and has high requirements for the safety and comprehensiveness of technology. Because once there are loopholes or defects in the entire information system, it will not only directly harm the system security, but will also cause confusion to the normal business work. Not only will there be property loss, but the life safety of many patients will also be threatened.

(2) The need for day-to-day hospital management.

Hospital operation management, in addition to the core medical service work, there are some non-business work, although these work can not play a supporting role, but it plays an important 
role in the normal operation of the hospital.

(3) The use of computer network technology for hospital information reform is the only way to promote their own development.

The use of computer network technology for hospital information reform can help the hospital to liberate itself from the traditional manual management, realize paperless and information-based hospital management, and achieve information sharing, including different departments or different departments in the same hospital. Different experts from the hospital shared the same patient's treatment information.

\section{Application of Computer Network Technology in Hospital Information Management}

Telemedicine diagnosis based on computer network.

Telemedicine diagnosis is the demand for medical development, and it is also a product of the combination of computer, network and communication, multimedia and database and other related technologies. It realizes the acquisition and encoding of audio and video information, the computerization of storage, and the online real-time transmission of audio and video information. Any computer connected to the network, as long as the corresponding software is installed and given authority, you can receive medical site information, remote consultation.

Warehouse and drug management.

The warehouse network system includes the drugstore management subsystem, which has the functions of import and export handling, inventory management, purchase plan generation, adjustment, audit, execution, query, drug search, drug catalog, drug price, price adjustment management, pharmaceutical accounting and system setting functions. . Can take the work mode of the doctor workstation, the patient first visits the hospital hall to establish "the visiting card" (the second grade A general hospital of this area is common), once again sees a doctor to carry "the visiting card" or to report the card number. After the introduction of electronic prescriptions, the link between drug stores and clinics has been strengthened, work efficiency has been improved, and procedures have been simplified, effectively reducing the burden of patient visits.

Computer network technology applied to hospital financial management system.

The strong data storage processing capability of computer network technology itself enables it to help hospital financial management establish a reliable system. The financial management system is an important part of the hospital as a social public organization. The hospital financial management works in the same way as the financial management activities of other companies and has its own characteristics. For example, the financial management activities of the hospital are very informative and have a strong comprehensiveness. Has the characteristics that other companies require accurate financial data. It is of great significance for hospitals to use computer network technology to establish financial management systems to improve the level of hospital financial management and cost accounting.

\section{Security problems in computer network hospital information network}

Problems with the computer network system itself

Although the computer network has been popularized in people's life and work, there are still some problems that cannot be escaped in practical applications. Some bad people will attack through the problems of the computer itself, and then complete their own goals. Although the computer network system can provide certain protection for itself, the protection scope is still relatively limited. For example, the computer network system itself has certain problems in the R\&D and design, which causes the computer network system to have low stability in practical applications.

Computer virus

When people use computers, the most annoying problem is that the network is suddenly in the middle or a black screen. The problem is that people often say computer poisoning. Computer viruses have a strong latent ability. Under normal circumstances, people will not find the virus at all and thus cannot handle it in time. 
Security issues in information network

At present, in order to be able to better integrate with consumers and show the image of the hospital, the hospital will create a website and implement the management of hospital information through the website. However, when the computer network is first started, there are many safety problems. The reason is that computer network funds and technologies are not very mature. Although new technologies are used to solve problems in practical applications, there are still some unavoidable problems.

\section{Strategies to solve network security problems by hospital information engineering}

Firewall technology

Researchers have conducted in-depth research on the problems of computers in practical applications, and then put forward some effective solutions, among which the most typical one is firewall technology. Firewalls have become popular in computers and can effectively isolate computers from viruses, install a protective film for computers, and reduce the impact of viruses on computer applications.

Anti-virus software

If the virus breaks through the firewall, it will inflict damage on the computer. In this case, you need to use anti-virus software. Anti-virus software is mainly to clean up the virus inside the computer. Currently there are many kinds of anti-virus software on the market, and what kind of anti-virus software is used has become a conceptual issue. People need to choose anti-virus software according to the performance of the computer so as to ensure that anti-virus software can really play a role in computers and maintain computers. Safety.

Management measures

Network security plays an important role in hospital informationization and can effectively improve the efficiency of hospital operations. If the computer network technology is applied in the construction of hospital information, then management is the most effective way to ensure network security. Therefore, hospitals should regulate the network management process and correctly understand the importance of network security. The hospital information construction is a huge and tedious hero. In the actual construction, it needs the guidance of the hospital management department, the government departments give encouragement in the policy, improve the intensity of information management, and configure a high-level team, so that the hospital can adapt to the times development of.

\section{Conclusion}

In a word, computer network technology is applied to the construction of information management in hospitals. It integrates various data information of hospitals to form a hospital information management system, which can realize the communication between various departments of the hospital. Computer networks have become the necessary hardware environment for modern hospital operations. The continuous development and improvement of computer network systems will also become an important part of hospital information construction. It not only improves work efficiency, optimizes work flow, saves manpower, and saves time; it improves the utilization of health resources; improves service quality; it automates the application of information acquisition, storage, and transmission, and comprehensive information classification and processing. The intensification of methods comprehensively reflects the health economy and the effectiveness of protection, and has promoted the comprehensive development of hospital informationization.

\section{References}

[1] Zhao Q G, Han L H, Rong-Rong W U, et al. Construction and Application of Real-time Visual Pharmaceutical Information Management Platform in Our Hospital[J]. China Pharmacy, 2014.

[2] Basso C, Calvignac J L, Vaidhyanathan N, et al. Analysis of network packets using a generated 
hash code[J]. 2015.

[3] Liu H T. Analysis of Formalism[J]. International Journal of Information \& Management Sciences, 2015, 26.

[4] Macedonio D, Merro M. A Semantic Analysis of Key Management Protocols for Wireless Sensor Networks[J]. Science of Computer Programming, 2011, 81(2):53-78.

[5] Pan J, Zhang N, Yao S, et al. Construction and Practice of Information Demonstration Area in Mentougou District of Beijing[C]// International Conference on Computer and Computing Technologies in Agriculture. Springer Berlin Heidelberg, 2010:367-373.

[6] Dong Y, Zhang P, Li W. Analysis of Informationization Construction of Business Financial Management under the Network Economy[M]// Advanced Research on Electronic Commerce, Web Application, and Communication. Springer Berlin Heidelberg, 2011:76-80.

[7] Liu Y. The application of computer networkinformationtechnology to enhance thelevelofconstruction project management[J]. Electronic Test, 2014.

[8] Lu D, Chen L Q, Qian X Y D, et al. Network-Based Construction of Open Virtual Laboratory Teaching Platform[C]// International Conference on Information Computing and Applications. Springer Berlin Heidelberg, 2011:427-433.

[9] Azevedo R C D, Ensslin L, Ant?nio Edésio Jungles. A Review of Risk Management in Construction: Opportunities for Improvement[J]. Modern Economy, 2014, 5(4):367-383.

[10]Jin C, Bai Y. Analysis on the Construction of Project Cost Information System[J]. Applied Mechanics \& Materials, 2014, 687-691:1979-1982.

[11] Drăgoi, M, Palaghianu, C, MironOnciul, M. Benefit, cost and risk analysis on extending the forest roads network: a case study in Crasna Valley (Romania).[J]. Annals of Forest Research, 2015, 58(1):333-345.

[12] Choi Y, Ye X, Zhao L, et al. Optimizing enterprise risk management: a literature review and critical analysis of the work of $\mathrm{Wu}$ and Olson[J]. Annals of Operations Research, 2016, 237(1-2):281-300. 